Otterbein University

Digital Commons @ Otterbein

$4-20-2018$

\title{
Motivational decline and recovery in higher education STEM courses
}

Anna M. Young

Otterbein University

Paul J. Wendel

Otterbein University

Joan M. Esson

Otterbein University

Kathryn M. Plank

Otterbein University

Follow this and additional works at: https://digitalcommons.otterbein.edu/edu_fac

Part of the Educational Assessment, Evaluation, and Research Commons, Engineering Education Commons, and the Science and Mathematics Education Commons

\section{Repository Citation}

Young, Anna M.; Wendel, Paul J.; Esson, Joan M.; and Plank, Kathryn M., "Motivational decline and recovery in higher education STEM courses" (2018). Education Faculty Scholarship \& Creative Works. 5. https://digitalcommons.otterbein.edu/edu_fac/5

This Article is brought to you for free and open access by the Education at Digital Commons @ Otterbein. It has been accepted for inclusion in Education Faculty Scholarship \& Creative Works by an authorized administrator of Digital Commons @ Otterbein. For more information, please contact digitalcommons07@otterbein.edu. 


\title{
Motivational decline and recovery in higher education STEM courses
}

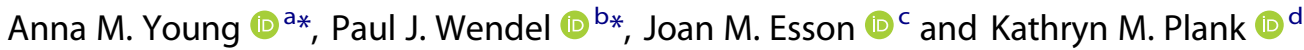 \\ ${ }^{\mathrm{a} D e p a r t m e n t}$ of Biology and Earth Science, Otterbein University, Westerville, OH, USA; ${ }^{\mathrm{b}}$ Department of \\ Education, Otterbein University, Westerville, OH, USA; 'Department of Chemistry, Otterbein University, \\ Westerville, $\mathrm{OH}, \mathrm{USA} ;{ }^{\mathrm{d}}$ Center for Teaching and Learning and Department of Education, Otterbein University, \\ Westerville, $\mathrm{OH}$, USA
}

\begin{abstract}
Decline in student motivation is a concern for STEM education, especially for underrepresented groups in the sciences. Using the Science Motivation Questionnaire II, 41 foundational STEM courses were surveyed at the beginning and end of each semester in an academic year at a small primarily undergraduate university. Significant pre- to post-semester declines were observed in each of five measured motivational factors (Intrinsic motivation, Career motivation, Self determination, Self-efficacy, and Grade motivation), with effect sizes ranging from 0.21 to 0.41 . However, in the second semester pre-survey, four motivational factors rebounded, including three returning to initial levels, suggesting that the observed motivational decline is not long-lasting. Analysis suggests that declines are not related to survey fatigue or student demographics, but rather to grades and, in the case of one motivational factor, to academic field. These findings suggest that a refocus on grading practices across STEM fields may influence student motivation and persistence in STEM.
\end{abstract}

\section{ARTICLE HISTORY}

Received 8 August 2017

Accepted 31 March 2018

\section{KEYWORDS}

Motivation; higher education; assessment; STEM

\section{Literature review}

In 2012, the U. S. President's Council of Advisors on Science and Technology set a goal of increasing the number of science, technology, engineering, and mathematics (STEM) bachelor's degrees by one million across a 10-year period (PCAST, 2012). The Council acknowledged that this goal is ambitious, but it could be met through a relatively modest improvement in the less than $40 \%$ persistence rate of students entering college as STEM majors. As STEM motivation is a critical contributor to student persistence (Simon, Aulls, Dedic, Hubbard, \& Hall, 2015), a better understanding of student motivation broadly across STEM disciplines and how it changes in introductory courses, where attrition is high (Daempfle, 2003), is essential to improving the number of students graduating with STEM degrees.

CONTACT Anna M. Young ayoung@otterbein.edu Department of Biology and Earth Science, Otterbein University, 1 South Grove Street, Westerville, OH, USA

*Both authors contributed equally to this work.

(4) Supplemental data for this article can be accessed https://doi.org/10.1080/09500693.2018.1460773. 
Consistent with Bandura's (1986) Social Cognitive Theory, motivation can be succinctly defined as 'an internal state that arouses, directs, and sustains goal-oriented behavior’ (Glynn, Brickman, Armstrong, \& Taasoobshirazi, 2011). The Science Motivation Questionnaire II (SMQII, Bryan, Glynn, \& Kittleson, 2011; Glynn et al., 2011; Glynn, Taasoobshirazi, \& Brickman, 2007) measures five motivation-related variables inspired by Social Cognitive Theory (Bandura, 1986, 1997). The SMQII devotes five items each to measure: Intrinsic motivation ('inherent satisfaction in learning science for its own sake'); Career motivation ('learning science as a means to [the] tangible end' of career establishment or advancement); Self determination ('the control students believe they have over their learning of science'); Self-efficacy ('students' beliefs that they can achieve well in science'); and Grade motivation ('learning science as a means to [the] tangible end' of high grades). In this paper, only SMQII factors will be indicated by italics, not general constructs.

Numerous researchers have produced evidence for a strong or moderate correlation between self-efficacy and academic achievement, both in K-12 education (Bryan et al., 2011) and postsecondary education (Multon, Brown, \& Lent, 1991; Richardson, Abraham, \& Bond, 2012; Robbins, Lauver, Davis, Davis, \& Langley, 2004; Valentine, DuBois, \& Cooper, 2004). Moderate correlations are observed between grade-motivation-related constructs and GPA (Richardson et al., 2012; Robbins et al., 2004). Moderate to weak correlations have also been identified between grade performance and the motivation constructs of intrinsic motivation and self determination (Bryan et al., 2011; Richardson et al., 2012).

Despite considerable interest in inherent student characteristics such as gender, race/ ethnicity, and first-generation status, the literature varies in breadth with respect to investigation of the connection between these characteristics and motivation.

\section{Gender}

Women pursue STEM at lower rates than men (Hill, Corbett, \& St. Rose, 2010; National Center for Science and Engineering Statistics, 2015). In addition, women graduate with fewer than one third of undergraduate degrees in mathematics, computer science, engineering, and the physical sciences (Wang \& Degol, 2013). A growing body of work suggests that cultural and societal factors drive this divide (Charles \& Bradley, 2009; Eccles, 2007; Nosek et al., 2009; Perez-Felkner, Nix, \& Thomas, 2017; Smith, Lewis, Hawthorne, \& Hodges, 2013; Spelke, 2005), and thus a change in culture and environment could close the gender gap in STEM fields.

For decades, a notable gender gap in STEM motivation has been observed in mathematics and the physical sciences (Eccles, Wigfield, \& Schiefele, 1998), especially for self-efficacy and the related concept of self-confidence (Litzler, Samuelson, \& Lorah, 2014). With respect to motivation, female students underestimate and/or male students over-estimate Self-efficacy (Glynn et al., 2011; Grunspan et al., 2016; MacPhee, Farro, \& Canetto, 2013; Schumm \& Bogner, 2016) while the reverse is seen for Self determination (Glynn et al., 2011; Schumm \& Bogner, 2016). This difference in Self determination may be indicative of an objective difference in work effort, as females exhibit greater academic selfdiscipline than males in K-12, earn more science and math credits and higher STEM grades in high school, and earn higher grade point averages on the postsecondary level 
(Duckworth \& Seligman, 2006; Hill et al., 2010; Richardson et al., 2012). It is unclear, however, how these types of motivation change over time.

\section{Race/ethnicity}

Underrepresented minority (URM) freshmen express an equal interest in majoring in STEM fields as white/Asian freshmen, yet they graduate in STEM fields at approximately half the rate of their white/Asian counterparts (Toven-Lindsey, Levis-Fitzgerald, Barber, \& Hasson, 2015). Moreover, $12 \%$ of the United States population is African-American, but the percentage of bachelor's degrees awarded to African-Americans range from 3-9\% for various STEM fields (Carnevale, Fasules, Porter, \& Landis-Santos, 2016).

Although few studies have examined STEM motivation among URM students, there is evidence that their motivation is positively correlated with their persistence from the first to second year of college (Allen, 1999). Among Hispanic students, the interactions between race/ethnicity, self-efficacy, achievement, and graduation are highly complex (Crisp, Nora, \& Taggart, 2009; Stevens, Olivarez, Lan, \& Tallent-Runnels, 2010), indicating a need for more research.

\section{First generation}

Unlike gender or race/ethnicity, first-generation status is not typically identifiable by other people, so while it is not as subject to outside forces that could affect motivation, such as racism or sexism, first-generation students may be unfamiliar with the 'hidden curriculum' (Margolis, 2001) of higher education. Compared to their continuing-generation counterparts, first-generation students tend to underperform (Stephens, Fryberg, Markus, Johnson, \& Covarrubias, 2012) and experience higher attrition than other students (D’Amico \& Dika, 2013). Also, URM and first-generation status often overlap, so separation of factors is sometimes impossible (Dika \& D'Amico, 2016).

First-generation students have exhibited lower self-efficacy and grade performance than continuing students (Ramos-Sánchez \& Nichols, 2007). However, the predictive relationship between motivation and academic performance among first-generation students is mixed (Próspero \& Vohra-Gupta, 2007; Ramos-Sánchez \& Nichols, 2007). That is, the role of motivation in achievement and attrition among first-generation students is less well studied, and less clear.

\section{Academic field}

Previous work examining affective differences among STEM disciplines has been conducted mostly at the primary or secondary level. A prominent study found that secondary students ranked interest in biology-related subjects above physical science subjects (Osborne, Simon, \& Collins, 2003), while a recent meta-analysis revealed no differences in attitude towards educational innovations by discipline among secondary students (Savelsbergh et al., 2016). However, consistent with the work of government investigations (e. g., PCAST, 2012) and National Science Foundation funding practices (NSF, 2017), studies do not necessarily attempt to disaggregate affective variables or instructional practices by STEM discipline (e. g., Furtak, Seidel, Iverson, \& Briggs, 2012; Stains et al., 2018). 
Consistent with its non-specific name, the Science Motivation Questionnaire (SMQII Glynn et al., 2011) is frequently used to either study students in STEM as a whole (Bryan et al., 2011, Schumm \& Bogner, 2016) or to examine students in the context of a single science subject (Glynn et al., 2011; Salta \& Koulougliotis, 2015). It is worthwhile to examine STEM as a whole in accordance with current convention and to look for differences among STEM disciplines to inform best practices.

\section{Motivational change over time}

Motivation for learning science has long been known to decline through early adolescence, a result typically attributed to cognitive and social development and/or increased student competition in later grades (Corpus, McClintic-Gilbert, \& Hayenga, 2009; Eccles et al., 1998; Juriševič, Glažar, Pucko, \& Devetak, 2008; Pintrich \& Schunk, 2002). However, few studies measure a general change in motivation to learn science and math between the beginning and end of post-secondary STEM education courses. Research measuring change in psychosocial variables for postsecondary students, particularly in STEM, typically focus on attitude which is not necessarily action-focused (see Gogolin \& Swartz, 1992; Huziak-Clark, Sondergeld, van Staaden, Knaggs, \& Bullerjahn, 2015; Jach \& Cervato, 2004; Sundberg, Dini, \& Li, 1994), rather than motivation which is always connected to action (Bandura, 1986; Fortus, 2014).

In studies of postsecondary STEM courses, multifactored motivational declines have been documented from the beginning to the end of an introductory chemistry course (Zusho, Pintrich, \& Coppola, 2003) and introductory biology classes and laboratories (Harris, 2009; Rybczynski, 2011; Rybczynski \& Schussler, 2013; Schruba, 2008). Particularly strong declines were observed for 'usefulness,' a variable closely related to Career motivation (Rybczynski \& Schussler, 2013), and for self-efficacy (Schruba, 2008). Zusho et al. (2003) and Schruba (2008) speculate that student discouragement stemming from class feedback and/or low grades may play a role in measured self-efficacy decline.

To inform science educators' efforts to improve motivation and retention, a broader study of how different inherent student characteristics may affect change in motivation over time is needed for a more holistic picture. Assessing motivational change is important, because while instructors do not directly affect a student's incoming motivation in a new course, instructors could impact how student motivation changes throughout the semester. Previous research provides support that inherent student characteristics do have a significant impact on student motivation, but they tend to focus on a general assessment of motivation and/or one course or discipline over a single semester. To our knowledge, there are no comprehensive studies that examine motivational change over a semester, resample students in a subsequent semester, cover multiple departments, and consider student demographics. Consequently, we conducted multidisciplinary assessment in foundational STEM courses, examining change in student motivation across an academic year, and the effects of grades and inherent student characteristics on motivation. The following represents a study at a small, midwestern, primarily undergraduate institution (PUI) via five motivation-related constructs related to Social Cognitive Theory (Bandura, 1986): Career, Grade, Intrinsic, Self determination and Selfefficacy (Glynn et al., 2011).

This study explores the following questions: 
(1) Does student motivation change over time across STEM disciplines?

(2) Does motivational decline result from survey fatigue (student exhaustion from repeated assessment)? If so, we predict that motivation scores will be lower for repeat takers vs first timers.

(3) Do grades affect motivation? If so, we predict a correlation between final course grade and pre- to post-semester change in motivation.

(4) Does academic field affect motivational change? If so, we predict that motivational trajectories will differ between the physical and natural sciences.

(5) Does motivational change vary across demographic subpopulations? We predict that motivational change across one or more semesters would differ for men vs. women, for white and Asian students vs. underrepresented minorities, and for first-generation vs. continuing-generation college students.

\section{Methods}

Over the fall and spring semesters of a single academic year, we administered the SMQ II (Glynn et al., 2011) to 41 class sections at a small PUI in the American Midwest (Supplementary Table 1). In contrast to previous post-secondary-level studies, which examined motivation-related factors in individual introductory science courses, the present study targeted all foundational STEM classes typically taken by science or math majors at this institution, 20 different courses in all. Items were customised based on the class (e. g., 'I am sure I can understand chemistry' rather than 'I am sure I can understand science'), and students were asked to respond relative to the particular class. Students rated their level of agreement with each of 25 statements on a 5-point Likert scale ranging from Never (coded as 1--note that Glynn et al. coded this as 0) to Always (coded as 5; Glynn et al. coded this as 4). Seven demographic questions were appended. Students taking more than one of the 41 class sections were surveyed in each course.

Students took the survey within the first two weeks of the semester (the 'pre-survey') and again within the last week of the semester or finals week (the 'post-survey'). The voluntary survey was administered with the oversight of our Institutional Review Board (IRB\#14/15-69). Ninety-two percent of students completed surveys, resulting in 1,157 pre- and/or post-surveys across the 41 classes. To assess change within a semester, we analyzed 828 matched pre-/post-survey pairs, 72\% of the maximum possible yield.

All statistical analyses were run in JMP or SPSS software. Although each SMQII item is measured on a 5-point ordinal scale, we follow standard practice in reporting means and standard deviations for theory-supported composite variables of validated and interrelated ordinal-scale items (Harrington, 2009; Lovelace \& Brickman, 2013). A pre- and postsurvey mean was calculated for the five questions composing each of the five variables measured by the SMQ II. Student answers for each of these five factors were averaged for the pre- and post-survey, and the difference in each average is hereafter referred to as change in motivation. Cronbach's alpha, a measurement of consistency for items within a variable, ranges from 0.84 to 0.86 on each of the five individual pre-survey and post-survey motivational factors, within the 'ideal' range of 0.8 to 0.9 (Lehman, O’Rourke, Hatcher, \& Stepanski, 2013).

As some students took the SMQII for more than one class (within a semester and/or across the two semesters), we have both a random effect (student ID) and fixed effects 
for academic field and our inherent student characteristics of interest based on selfreported data: first generation status (yes or no), gender (male or female), and race and ethnicity (underrepresented minority [URM] or caucasian/Asian), and the interaction of these variables. Consequently we determined effects of inherent student characteristics through a generalised linear mixed model (GLMM), run separately for each factor's pre- to post change in motivation $(N=828)$. For any independent variable (academic field, gender, race/ethnicity, first-generation status) that yielded significant results in the GLMM, we then ran either a nested, repeated measures analysis of variance (ANOVA) or a multivariate repeated measures analysis of variance (MANOVA) to look for differences among groups in change over time.

\section{Results}

\section{Does student motivation change over time across STEM disiplines?}

A pre- to post-semester decline in each of the five SMQ II motivational factors was observed for students taking introductory STEM courses across a variety of disciplines. As the data were not normally distributed, we performed Wilcoxon signed rank tests on combined-semester data for the 828 cases of students taking both pre- and postsurveys across either semester in the 41 foundational STEM class sections. Differences were significant $(p<0.001)$ after a Holm-Bonferroni correction for multiple comparisons (Figure 1, Supplementary Table 2). Effect sizes are small to medium: Intrinsic motivation $r$ $=0.32$, Career motivation $r=0.41$, Self determination $r=0.21$, Self-efficacy $r=0.41$, and Grade motivation $r=0.32$.

To check for motivational change across the academic year, we pared down our matched data set to include only students who took pre- and post- surveys across both semesters. To address the concern that a student taking a spring class unrelated to courses taken in the fall, that is, a 'new' subject, may simply be more motivated by the new subject, we generated a subset of students taking sequential introductory courses in the same discipline. These include two-course introductory sequences in biology $(N=$

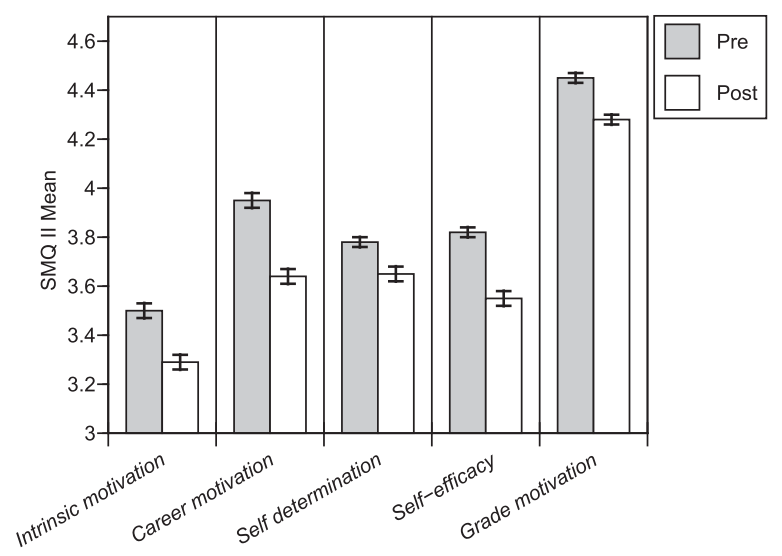

Figure 1. Mean pre-survey and post-survey SMQ II results for the academic year for student completing both pre- and post-surveys $(N=828)$. 
$30)$, chemistry $(N=76)$, organic chemistry $(N=12)$, algebra-based physics $(N=18)$, calculus-based physics $(N=17)$, and pre-calculus/calculus $(N=15)$. For the resulting 168 cases, we calculated mean pre- and post-survey factor scores in each semester (Figure 2). Students taking multiple courses were represented more than once.

Among these 168 cases of students in sequential introductory courses, we found a fall semester decline of Intrinsic motivation, Self-efficacy, and Grade motivation and a complete recovery following winter break, only 4-7 weeks later. We also observed a decline in the fall and partial recovery of Career motivation following winter break. We used a one-way ANOVA with repeated measures to compare changes in each motivation factor between each time interval (fall semester change, winter break change, spring semester change). We found significant differences across time for changes in Intrinsic motivation $\left(F_{2,166}=9.41, p<0.0001\right)$, Career Motivation $\left(F_{2,166}=12.95, p<0.0001\right)$, Selfefficacy $\left(F_{2}, 166=18.29, p<0.0001\right)$, and Grade Motivation $\left(F_{2}, 166=4.89, p=0.0086\right)$, but no significant difference across time for Self determination. Next, for all but Self determination we used Wilcoxon matched pairs signed-rank tests to confirm significant declines between fall pre-survey and fall post-survey scores $(S>1441.5, \mathrm{df}=167, p<$ 0.01 ), generally confirming the overall pre- to post-semester motivational decline reported above. Of these four motivation factors, Wilcoxon matched pairs signed-rank tests indicate no significant differences between fall pre-survey and spring pre-survey scores, signalling complete recovery over winter break for Intrinsic motivation, Self-efficacy, and Grade motivation. Career motivation increased over winter break $(S=1299.5, \mathrm{df}=267$, $p=0.019)$, but did not recover to fall pre-survey levels $(S=1591.5, \mathrm{df}=167, p=0.005)$.

Another subset counters the notion that course novelty causes motivational recovery: Because of poor grades, seven students took Calculus I in the fall (average grade $=0.43$ / 4.00 ) and then took it again in the spring semester (average grade $=2.71 / 4.00$ ). From the end of their poor fall term until the beginning of the spring term, even these students experienced a motivational recovery on all factors except Grade motivation

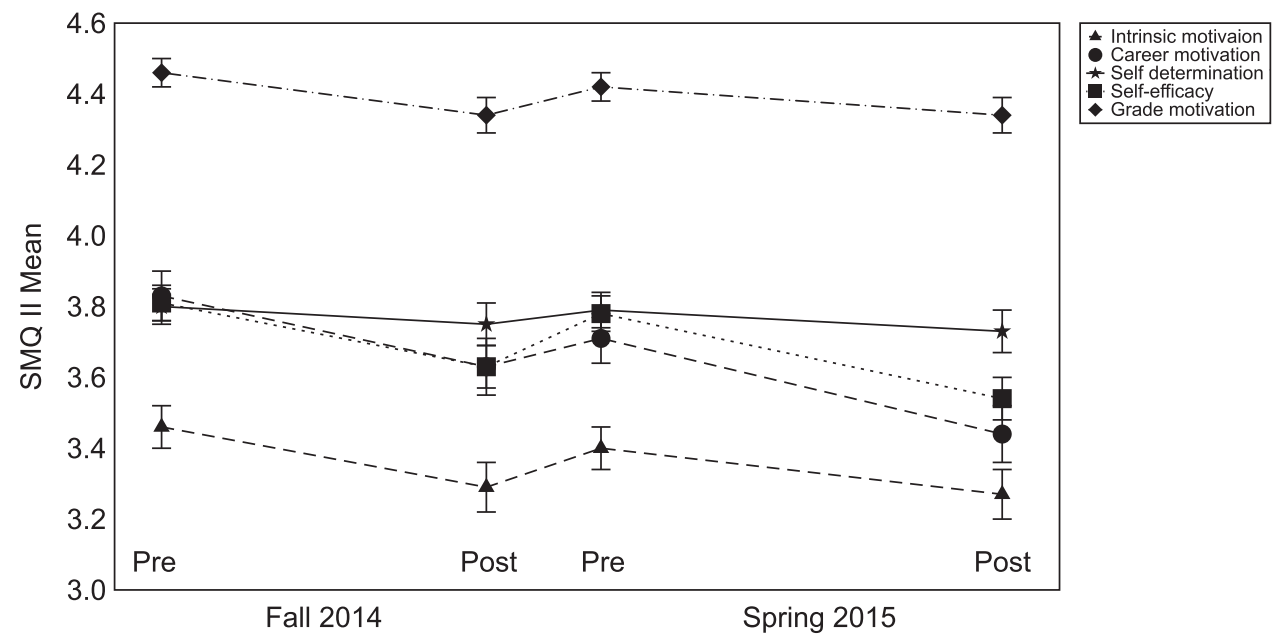

Figure 2. Comparison of SMQ II factor means for students successively completing both semesters of a sequential introductory course (Biology I/II, Chemistry I/II, Algebra-based Physics I/II, Calculus-based Physics I/II, and/or Pre-Calculus/Calculus; $N=168$ ). 
(Supplementary Figure 1). Such motivation recovery, even when retaking a course for grade replacement, supports the robustness of the between-semester recovery described above and provides counter-evidence to the notion that excitement over a new subject is at work.

\section{Exploring explanations for change}

\section{Does motivational decline result from survey fatigue?}

A possible explanation for motivational decline observed here and in previous studies is student survey fatigue, that is, having taken previous surveys affects subsequent motivational factors. To test this, we compared spring pre-surveys for students taking the survey for the first time to those who had taken the survey at least once previously $(N$ $=12$ each), drawn from mathematics/computer science, as most science courses are taught in a yearlong sequence. A Wilcoxon signed rank test indicated no differences in pre-motivation surveys for the two groups, providing counter-evidence to survey fatigue in the observed pre- to post-semester declines.

\section{Do grades affect motivation?}

A moderate correlation between change in Self-efficacy and final course grade is observed for students taking both pre- and post-surveys across either semester, with higher final grade correlating to smaller motivational declines (Table 1). Smaller correlations are observed between final course grade and changes in three of the remaining four motivation factors. Since motivational decline was primarily driven by lower-achieving students in a study of a college chemistry course (Zusho et al., 2003), we divided students into highachievers (earning course grades of A to A-), medium achievers (earning course grades of $\mathrm{B}+$ to $\mathrm{C}-$ ), and low achievers (earning course grades of $\mathrm{D}+$ to $\mathrm{F}$ ). A one-way nested ANOVA (nesting student ID within grade as a random effect) indicates that all three achievement classes are distinct in all motivation factors except Self determination (Table 2). In Self-efficacy, the most grade-sensitive of the factors (Table 1), the highachieving students actually exhibited a modest pre- to post-course increase in Self-efficacy (also observed by Zusho et al., 2003), while the low-achieving students exhibited a very strong decline in Self-efficacy. It is notable, however, that a similar pattern is visible in nearly all of the remaining motivation factors: high-achieving students exhibit modest motivational declines, medium-achieving students exhibit stronger motivational declines, and low-achieving students exhibit far greater motivational declines.

Table 1. Correlation between changes in SMQ II Motivation scores and final course grades, $N=828$. As all motivational changes are negative, positive Spearman's $\rho$ values indicate that higher grades correspond to smaller motivational declines.

\begin{tabular}{ll}
\hline Factor & \multicolumn{1}{c}{$\rho$} \\
\hline$\Delta$ Intrinsic motivation & $0.161^{* * *}$ \\
$\Delta$ Career motivation & $0.137^{* * *}$ \\
$\Delta$ Self determination & 0.056 \\
$\Delta$ Self-efficacy & $0.387^{* * *}$ \\
$\Delta$ Grade motivation & $0.241^{* * *}$ \\
\hline$* * * 0.0001$. &
\end{tabular}


Table 2. One-way nested ANOVA comparing mean changes in motivation factors among high achieving students earning $A / A-(N=257)$, medium achievers earning $B+/ B / B-/ C+/ C / C-(N=483)$, and low achievers earning $D+/ D / F(N=88)$.

\begin{tabular}{lccccc}
\hline Change in Factor & High Achievers & Medium Achievers & Low Achievers & $F$ value & Effect size $\left(\eta_{p}^{2}\right)$ \\
\hline$\Delta$ Intrinsic motivation & -0.080 & -0.228 & -0.464 & $11.72^{* * *}$ & 0.08 \\
$\Delta$ Career motivation & -0.200 & -0.293 & -0.663 & $14.27^{* * *}$ & 0.12 \\
$\Delta$ Self determination & -0.092 & -0.118 & -0.266 & 2.56 & 0.02 \\
$\Delta$ Self-efficacy & +0.018 & -0.339 & -0.752 & $46.96^{* * *}$ & 0.26 \\
$\Delta$ Grade-motivation & -0.037 & -0.177 & -0.481 & $25.06^{* * *}$ & 0.19 \\
\hline
\end{tabular}

${ }^{* * *} p<0.0001$.

\section{Does academic field affect motivational change?}

Course discipline was only found to impact student motivation for Self determination. In order to explore Self determination, we ran a multivariate repeated-measures analysis (MANOVA) on Self determination for the matched data set including only students who took pre- and post- surveys across both semesters $(N=168)$, looking at how time of change (fall, winter, and spring), sequential course topic, and their interaction, affects change in Self determination. Significant differences were observed for Self determination changes by course $\left(F_{5}, 162=4.522, p=0.0007\right)$ and by interaction between time and course $\left(F_{10,324}=3.287, p=0.0005\right)$, indicating that course influences gain or loss of Self determination across different time periods. Tukey post-hoc tests indicate that the largest differences among courses occurred in the spring; both physics course sequences demonstrated the largest increases while biology and pre-calculus/calculus demonstrated the largest decreases (Figure 3). On average across the year, we find that introductory physics and chemistry students experienced the largest increases in Self determination (change \pm 0.25 for algebra-based physics, +0.13 for calculus-based physics, and

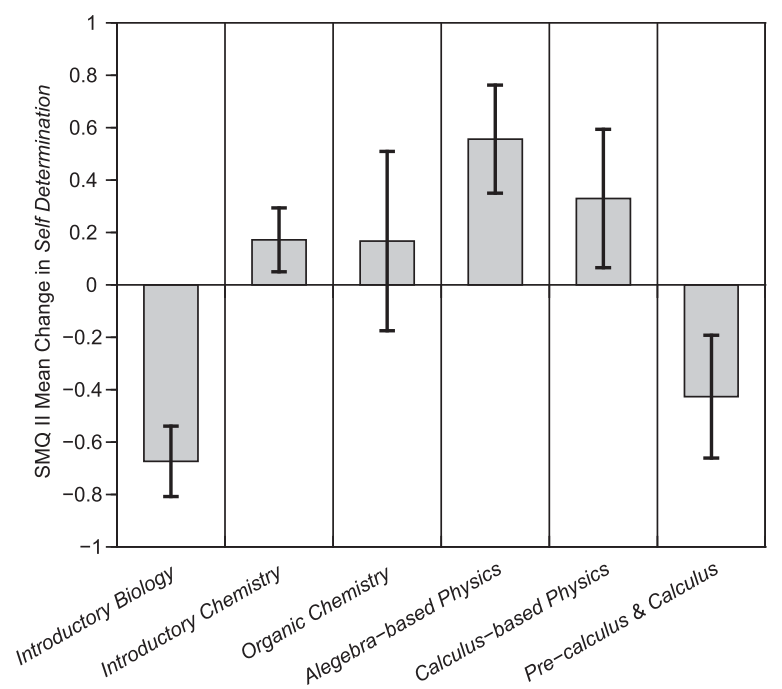

Figure 3. SMQ II factor mean change for Self determination in the Spring term by sequential introductory course (Biology I/II, Chemistry I/II, Algebra-based Physics I/II, Calculus-based Physics I/II, and/or PreCalculus/Calculus; $N=168$ ). 
+0.05 for chemistry), while biology students experienced the most dramatic decreases in Self determination (change $=-0.25$ ).

\section{Does motivation change vary across demographic subpopulations?}

In the GLMM, no statistically significant effects were observed for changes in any of the five motivation factors by gender, under-represented minority status, or first-generation status. As has been previously observed, we found that Self determination was higher for women $\left(\operatorname{mean}_{\mathrm{pre}}=3.83 \pm 0.03\right.$, mean $\left._{\text {post }}=3.72 \pm 0.03\right)$ than for men $\left(\operatorname{mean}_{\text {pre }}=3.64\right.$ \pm 0.04, mean $\left._{\text {post }}=3.47 \pm 0.04\right)$ and Self-efficacy was higher for men $\left(\operatorname{mean}_{\text {pre }}=3.99 \pm\right.$ 0.04, mean $\left._{\text {post }}=3.71 \pm 0.05\right)$ than for women $\left(\right.$ mean $_{\text {pre }}=3.71 \pm 0.03$, mean $_{\text {post }}=3.42 \pm$ 0.03 ) but no differences in motivational change were observed for either factor.

\section{Discussion}

\section{Motivational decline and recovery}

We observe substantial within-semester declines in five motivational factors measured collectively across 41 STEM class sections in seven STEM disciplines (Supplementary Table 1). This pattern is akin to previous single-subject studies (Harris, 2009 Rybczynski, 2011; Rybczynski \& Schussler, 2013; Schruba, 2008; Zusho et al., 2003;), but in the current study, we sampled more broadly across multiple STEM fields and across a complete academic year. We observed a decline and complete recovery of Intrinsic motivation, Self-efficacy, and Grade motivation by the beginning of the succeeding semester, 4 to 7 weeks later, a decline and partial recovery of Career motivation, and no differences in change of Self determination across the three time intervals.

These data indicate that prior concern regarding de-motivating effects of STEM coursework may be misplaced. For example, where Zusho et al. (2003) observed within-semester decline in Self-efficacy among chemistry students and suggested efforts to counter this trend, our results suggest that Self-efficacy may fully recover by the beginning of the following semester without intervention. Similarly, studies have documented a greater motivational decline among students completing inquiry-based biology laboratories compared to conventional biology laboratories (Harris, 2009; Rybczynski, 2011; Rybczynski \& Schussler, 2013). Further study is needed to determine whether motivational decline and recovery have long-lasting consequences, such as Smith et al.'s (2013) finding that perceived effort (akin to Self determination) has downstream effects on women's motivation to remain in STEM fields.

\section{Survey fatigue}

Repeated survey of the same participants can lead to a decrease in participation (Porter, Whitcomb, \& Weitzer, 2004), and in the context of an affective variable such as motivation, we speculated that following the initial survey, fatigue might lead to a lower reported motivation. However, we did not observe a greater-than-expected decrease in participation from the beginning to the end of the semester ( $72 \%$ of students completing a pre-survey also completed a post-survey). There was no difference in motivation scores 
for first time and repeat takers (albeit with a low sample size), and for students taking surveys at all four time points in sequential introductory courses, we observed a recovery in student motivation at the beginning of the spring semester, the third time point students had taken the survey. Together, these provide counter-evidence to the speculation that survey fatigue contributes substantially to the observed pre- to post-semester decline in motivation.

\section{Grades}

We measured a significant correlation between semester decline and final course grades in four of the five motivational factors (Table 1), of which Self-efficacy and Grade motivation have been strongly associated with grades in previous work (Multon et al., 1991; Richardson et al., 2012; Robbins et al., 2004; Valentine et al., 2004). These findings support the notion that grade discouragement leads to within-semester motivational declines, although we cannot rule out the possibility that lower motivation leads students to earn lower grades. The latter would suggest that supporting student motivation, by whatever means, would lead to higher achievement, and possibly higher retention (Griffith, 2010; Simon et al., 2015). If, on the other hand, midterm grade discouragement leads to motivational decline, midterm assessments (which were not available in this study) could be examined for validity, necessity, and frequency. Rask (2010) has even suggested that science educators could redistribute grades more akin to non-STEM disciplines to increase STEM retention. At a minimum, faculty development in STEM should include discussion of motivation and mid term assessments.

\section{Academic field}

Among sequential introductory courses, we observed differences by academic field only for changes in Self determination in the spring (second) semester of the two-course sequences (Figure 3). In the spring semester, physics and chemistry (physical science) students reported increases while biology (natural science) students reported decreases in Self determination, despite beginning at statistically indistinguishable pre-survey levels. These results indicate that over the semester, these particular university students experienced a decreased willingness to invest effort into learning natural sciences, but an increased willingness to invest effort into learning physical sciences. These changes in motivation are somewhat unexpected given Osborne et al.'s (2003) finding that secondary students 'like' biology more than chemistry and physics, but as Bandura (1986) argued, affinity for something is not the same as motivation to act.

Patterns of decline in Self determination by specific classes or topics could be attributed to disillusionment with or lack of interest in the subject, or instructors' varied abilities to engage students (Skinner \& Belmont, 1993). Given our small institution, we cannot disentangle these various possibilities, or the effect of student culture or grading practices, which may, in turn, interact with student motivation and inherent student characteristics. For example, women's higher Self determination may contribute to greater female student success in a class whose grades emphasise effort over, say, conceptual understanding. Further investigation would be of interest to see whether the same individuals' motivation differs by course and whether these discipline patterns are replicated at other institutions. 


\section{Demographics}

For demographic variables we observed no effect of gender, race/ethnicity, or first generation status on motivational change. However, similar to previous studies (Glynn et al., 2011; Salta \& Koulougliotis, 2015; Schumm \& Bogner, 2016), we observed higher Self determination in female than male students, no difference in Grade motivation between women and men, but lower Self-efficacy among women than men. Since Self-efficacy strongly correlates to academic success in previous studies (see Literature Review), and since post-survey Self-efficacy results correlate strongly to course grade in the present study (Spearman's $\rho=0.49, p<.0001$ overall; $\rho=0.52, p<.0001$ for females; $\rho=0.49, p$ $<.0001$ for males), one would expect males to earn correspondingly higher grades than females. However, a Wilcoxon Signed Rank Test does not reveal a course grade difference between males (mean $\pm \mathrm{SD}=2.75 \pm 1.07, N=296$ ) and females (mean $\pm \mathrm{SD}=2.85 \pm 0.97$, $N=529 ; S=118494.5 ; z=1.15, p=0.25$ ), indicating that women's higher perceived effort levels are not rewarded. This, in turn, returns us to questions of grading practices. Does a course grade primarily reward conceptual understanding and problem-solving ability, or does it primarily reward hard work, reflected in course attendance, submission of assignments on time, etc., or some mixture of the two? Instructor reflection on where their course might be on this continuum could inform interventions, such as showing anonymous grade data from past semesters broken out by gender, to illustrate to everyone that females are just as capable as males. If there was more levelling of confidence, facilitated by this or other interventions, perhaps this would support greater retention of women in STEM, and more equitable treatment of them by their male counterparts.

Given substantial differences in end-of-course course grades between our underrepresented minority students (mean $\pm \mathrm{SE}=2.16 \pm 0.13, N=55$ ) and our white/Asian students (mean $\pm \mathrm{SE}=2.86 \pm 0.04, N=769 ; S=15923.5 ; Z=4.00 ; p<0.0001$ ), it is surprising that no corresponding differences were found in motivational change between URM and white/Asian students. This indicates that grade discouragement may not be a driving factor for motivational change among under-represented minorities. One possible explanation is that factors not measured in the current study interact with motivational and demographic variables in complex ways. For example, several studies suggest that among some URM students, social support, rather than motivation, may be the predominant factor for academic performance in STEM (Dennis, Phinney, \& Chuateco, 2005; Phinney \& Hass, 2003; Young, Johnson, Hawthorne, \& Pugh, 2011), warranting a different kind of assistance, such as a support group.

We found that continuing generation students have significantly higher STEM grades (mean $\pm \mathrm{SE}=2.86 \pm .04, N=583$ ) compared to first generation students (mean $\pm \mathrm{SE}=$ $2.57 \pm .08, N=176 ; S=58674.5, Z=3.246 ; p=0.0012$ ), akin to Ramos-Sánchez and Nichols (2007). Since previous research indicates strong correlations between self-efficacy and academic performance, it is surprising that we observed no differences in Self-efficacy change, or any other motivational factor, between first-generation and continuing-generation students. Our findings run counter to previously observed differences between firstand continuing-generation students (Ramos-Sánchez \& Nichols, 2007), suggesting that first-generation students who commit to attend a private liberal arts university such as the one sampled here may be especially highly motivated to do so without the familiarity bestowed by parents of continuing generation students. 


\section{Other explanations for motivational decline}

Since motivational decline is regarded as a reduction in an internal state that is impacted by external factors, our observation of a systematic motivational decline points toward shared external factors. We have presented counter evidence for survey fatigue and support for grades and academic field as factors that affect motivation. Other potential explanations for the observed patterns of motivational change generate interesting hypotheses for future investigation. Exhaustion is an alternative explanation for the observed within-semester motivational decline, which may be due to increased end-ofterm student workload or even faculty exhaustion (Radel, Sarrazin, Legrain, \& Wild, 2010). Future studies may examine this relationship, for example, by comparing students with higher workloads or increased out-of-class demands to those with lower workloads or fewer out-of-class demands.

\section{Limitations}

It should be noted that in order to examine changes in motivation across a semester, only data for students who completed both a pre- and post- survey could be used. Comparing students completing both the pre- and post-survey to students completing the pre-survey only, a chi-square test indicates no differences in participation by any student demographic factor. However, students completing both the pre- and post-survey had substantially higher course grades (mean $\pm \mathrm{SE}=2.84 \pm 0.04$ ) compared to students completing the pre-survey only (mean $\pm \mathrm{SE}=1.89 \pm 0.08 ; S=46824, Z=9.06, p<0.0001$ ). This finding isn't surprising, as these surveys were administered in class, and failure to complete a post-survey may indicate that these students did not consistently attend class at the end of the semester, which could also explain their lower final grade. Post-motivation may be lower among students not sampled in this study, but this risk is relatively modest given our high participation rate. Similarly, students who do not persist in STEM beyond the first semester are not represented among the subset of students taking sequential introductory courses, thereby likely over-representing higher-achieving students, which may inflate the measured motivational recovery over winter break. A valuable future study would track students who do not persist in STEM beyond the first semester to assess their motivational recovery over winter break.

\section{Conclusion}

This study is the first to our knowledge that sampled motivation across multiple semesters and disciplines for college students. We witnessed a decline in motivational factors of interest, and notably, a rebound between semesters. In the fundamental STEM courses that we examined, student motivation was linked to grades, and academic field was linked only to Self determination. Future work needs to be done to address the predictions generated in the alternative hypothesis regarding exhaustion, which could in turn suggest university interventions to help reduce demands on students. Since four of the five motivational factors are not affected by STEM discipline, faculty development to address student motivation does not need to be discipline-based, but can be addressed to a broad STEM faculty audience. Although development of an effective intervention 
regarding grades and motivation depends upon disentangling the direction of causality, it is possible that faculty development addressing alterations in assessment practices could be fruitful to help maintain students in STEM disciplines (Rask, 2010; Simon et al., 2015).

\section{Acknowledgements}

We thank the dedicated, faculty, staff, and students at Otterbein University who made this research possible, especially Morgan Price, Ashley Putnam, Susan Thompson, Matt Grote, Aaron Reinhardt, Robin Grote, Wendy Johnston, Simon Lawrance, and Troy Markham. We are also grateful for the helpful comments of an anonymous reviewer.

\section{Disclosure statement}

No potential conflict of interest was reported by the authors.

\section{Funding}

This research was supported by the National Science Foundation under grant number DUE 1347243; Division of Undergraduate Education.

\section{ORCID}

Anna M. Young (D) http://orcid.org/0000-0003-3321-1878

Paul J. Wendel (D) http://orcid.org/0000-0003-2136-6610

Joan M. Esson (1D) http://orcid.org/0000-0003-1412-826X

Kathryn M. Plank (D) http://orcid.org/0000-0002-1601-7232

\section{References}

Allen, D. A. (1999). Desire to finish college: An empirical link between motivation and persistence. Research in Higher Education, 40, 461-485. doi:10.1023/A:1018740226006

Bandura, A. (1986). Social foundations of thought and action: A social cognitive theory. Englewood Cliffs, NJ: Prentice-Hall, Inc.

Bandura, A. (1997). Self-efficacy: The exercise of control. New York: W. H. Freeman \& Co.

Bryan, R. R., Glynn, S. M., \& Kittleson, J. M. (2011). Motivation, achievement, and advance placement intent of high school students learning science. Science Education, 95, 1049-1065. doi:10. 1002/sce.20462

Carnevale, A. P., Fasules, M. L., Porter, A., \& Landis-Santos, J. (2016). African Americans: College majors and earnings. Washington, DC: Georgetown University Center on Education and the Workforce. https://cew.georgetown.edu/wp-content/uploads/AfricanAmericanMajors_2016_ web.pdf

Charles, M., \& Bradley, K. (2009). Indulging our gendered selves? Sex segregation by field of study in 44 countries. American Journal of Sociology, 114(4), 924-976. doi:10.1086/595942

Corpus, J. H., McClintic-Gilbert, M. S., \& Hayenga, A. O. (2009). Within-year changes in children's intrinsic and extrinsic motivational orientations: Contextual predictors and academic outcomes. Contemporary Educational Psychology, 34(2), 154-166. doi:10.1016/j.cedpsych.2009.01.001

Crisp, G., Nora, A., \& Taggart, A. (2009). Student characteristics, pre-college, college, and environmental factors as predictors of majoring in and earning a STEM degree: An analysis of students attending a Hispanic serving institution. American Educational Research Journal, 46(4), 924-942. doi:10.3102/0002831209349460 
Daempfle, P. (2003). An analysis of high attrition rates among first year college science, math, and engineering majors. Journal of College Student Retention: Research, Theory, and Practice, 5, 3752. doi:10.2190/DWQT-TYA4-T20W-RCWH

D’Amico, M. M., \& Dika, S. L. (2013). Using data known at the time of admission to predict firstgeneration college student success. Journal of College Student Retention: Research, Theory \& Practice, 15(2), 173-192. doi:10.2190/CS.15.2.c

Dennis, J. M., Phinney, J. S., \& Chuateco, L. I. (2005). The role of motivation, parental support, and peer support in the academic success of ethnic minority first-generation college students. Journal of College Student Development, 46(3), 223-236. The Johns Hopkins University Press. Retrieved from Project MUSE database.

Dika, S. L., \& D’Amico, M. M. (2016). Early experiences and integration in the persistence of firstgeneration college students in STEM and non-STEM majors. Journal of Research in Science Teaching, 53(3), 368-383. doi:10.1002/tea.21301

Duckworth, A. L., \& Seligman, M. E. P. (2006). Self-discipline gives girls the edge: Gender in selfdiscipline, grades, and achievement test scores. Journal of Educational Psychology, 98(1), 198208. doi:10.1037/0022-0663.98.1.198

Eccles, J. S. (2007). Where are all the women? Gender differences in participation in physical science and engineering. In S. J. Ceci, \& W. M. Williams (Eds.), Why aren't more women in science? Top researchers debate the evidence (pp. 199-210). Washington, DC: American Psychological Association.

Eccles, J. S., Wigfield, A., \& Schiefele, U. (1998). Motivation to succeed. In W. Damon \& N. Eisenberg (Eds.), Handbook of child psychology (Vol. 3, pp. 1017-1095). New York: John Wiley \& Sons, Inc.

Fortus, D. (2014). Attending to affect. Journal of Research in Science Teaching, 51(7), 821-835. doi:10.1002/tea.21155

Furtak, E. M., Seidel, T., Iverson, H., \& Briggs, D. C. (2012). Experimental and quasi-experimental studies of inquiry-based science teaching: A meta-analysis. Review of Educational Research, 82 (3), 300-329. doi:10.3102/0034654312457206

Glynn, S. M., Brickman, P., Armstrong, N., \& Taasoobshirazi, G. (2011). Science motivation questionnaire II: Validation with science majors and nonscience majors. Journal of Research in Science Teaching, 48(10), 1159-1176. doi:10.1002/tea.20442

Glynn, S. M., Taasoobshirazi, G., \& Brickman, P. (2007). Nonscience majors learning science: A theoretical model of motivation. Journal of Research in Science Teaching, 44, 1088-1107. doi:10.1002/tea.20181

Gogolin, L., \& Swartz, F. (1992). A quantitative and qualitative inquiry into the attitudes toward science of nonscience college students. Journal of Research in Science Teaching, 29(5), 487-504.

Griffith, A. L. (2010). Persistence of women and minorities in STEM field majors: Is it the school that matters? Economics of Education Review, 29, 911-922. doi:10.1016/j.econedurev.2010.06.010

Grunspan, D. Z., Eddy, S. L., Brownell, S. E., Wiggins, B. L., Crowe, A. J., Goodreau, S. M., \& Rosenfeld, C. S. (2016). Males under-estimate academic performance of their female peers in undergraduate biology classrooms. PLoS ONE, 11(2), e0148405. doi:10.1371/journal.Pone. 0148405

Harrington, D. (2009). Confirmatory factor analysis. New York: Oxford University Press.

Harris, M. A. (2009). Investigation into the effectiveness of an inquiry-based curriculum in an introductory biology laboratory. (Master of Science in Teaching). University of Maine. Retrieved from http://www.umaine.edu/center/files/2009/12/Harris_thesis.pdf

Hill, C., Corbett, C., \& St. Rose, A. (2010). Why so few? Women in science, technology, engineering, and mathematics. Washington, DC: American Association of University Women.

Huziak-Clark, T., Sondergeld, T., van Staaden, M., Knaggs, C., \& Bullerjahn, A. (2015). Assessing the impact of a research-based STEM program on STEM majors' attitudes and beliefs. School Science and Mathematics, 115(5), 226-236. doi:10.1111/ssm.12118

Jach, J. Y., \& Cervato, C. (2004). Attitude toward learning science of students in introductory geology courses. Teaching Earth Science, 29(2), 28-31. 
Juriševič, M., Glažar, S. A., Pucko, C. R., \& Devetak, I. (2008). Intrinsic motivation of pre-service primary school teachers for learning chemistry in relation to their academic achievement. International Journal of Science Education, 30(1), 87-107. doi:10.1080/09500690601148517

Lehman, A., O’Rourke, N., Hatcher, L., \& Stepanski, E. (2013). JMP ${ }^{\circledR}$ for basic univariate and multivariate statistics: Methods for researchers and social scientists (2nd ed.). Cary, NC: SAS Institute, Inc.

Litzler, E., Samuelson, C. C., \& Lorah, J. A. (2014). Breaking it down: Engineering student STEM confidence at the intersection of race/ethnicity and gender. Research in Higher Education, 55, 810-832. doi:10.1007/s11162-014-9333-Z

Lovelace, M., \& Brickman, P. (2013). Best practices for measuring students' attitudes toward learning science. CBE-Life Sciences Education, 12, 606-617. doi:10.1187/cbe.12-11-0197

MacPhee, D., Farro, S., \& Canetto, S. S. (2013). Academic self-efficacy and performance of underrepresented STEM majors: Gender, ethnic, and social class patterns. Analyses of Social Issues and Public Policy, 13, 347-369. doi:10.1111/asap.12033

Margolis, E. (Ed.). 2001. The hidden curriculum in higher education. New York: Routledge.

Multon, K. D., Brown, S. D., \& Lent, R. W. (1991). Relation of self-efficacy beliefs to academic outcomes: A meta-analytic investigation. Journal of Counseling Psychology, 38(1), 30-38. doi:10. 1037/0022-0167.38.1.30

National Center for Science and Engineering Statistics. (2015). Women, minorities, and persons with disabilities in science and engineering. Washington, DC: National Science Foundation.

National Science Foundation. (2017). Improving undergraduate STEM education: Education and human resources (IUSE: EHR). Retrieved from https://www.nsf.gov/pubs/2017/nsf17590/ nsf17590.htm

Nosek, B. A., Smyth, F. L., Sriram, N., Lindner, N. M., Devos, T., Ayala, A., ... Greenwald, A. G. (2009). National differences in gender-science stereotypes predict national sex differences in science and math achievement. Proceedings of the National Academy of Sciences, 106(26), 10593-10597. doi:10.1073/pnas.0809921106

Osborne, J., Simon, S., \& Collins, S. (2003). Attitudes toward science: A review of the literature and its implications. International Journal of Science Education, 25(9), 1049-1079. doi:10.1080/ 0950069032000032199

Perez-Felkner, L., Nix, S., \& Thomas, K. (2017). Gendered pathways: How mathematics ability beliefs shape secondary and postsecondary course and degree field choices. Frontiers in Psychology, 8, 386. doi:10.3389/fpsyg.2017.00386

Phinney, J. S., \& Hass, K. (2003). The process of coping among ethnic minority first-generation college freshmen: A narrative approach. The Journal of Social Psychology, 143(6), 707-726. doi:10.1080/00224540309600426

Pintrich, P. R., \& Schunk, D. H. (2002). Motivation in education: Theory, research, and applications (2nd ed.). Upper Saddle River, NJ: Merrill/Prentice Hall.

Porter, S. R., Whitcomb, M. E., \& Weitzer, W. H. (2004). Multiple surveys of students and survey fatigue. New Directions for Institutional Research, 2004(121), 63-73. doi:10.1002/ir.101

President's Council of Advisors on Science and Technology, Executive Office of the President. (2012). Engage to excel: Producing one million additional college graduates with degrees in science, technology, engineering, and mathematics, Technical Report. https://www.whitehouse. gov/sites/default/files/microsites/ostp/pcast-engage-to-excel-final_feb.pdf

Próspero, M., \& Vohra-Gupta, S. (2007). First generation college students: Motivation, integration, and academic achievement. Community College Journal of Research and Practice, 31, 963-975. doi:10.1080/10668920600902051

Radel, R., Sarrazin, P., Legrain, P., \& Wild, T. C. (2010). Social contagion of motivation between teacher and student: Analyzing underlying processes. Journal of Educational Psychology, 102 (3), 577-587. doi:10.1037/a0019051

Ramos-Sánchez, L., \& Nichols, L. (2007). Self-efficacy of first-generation and non-first-generation college students: The relationship with academic performance and college adjustment. Journal of College Counseling, 10, 6-18. doi:10.1002/j.2161-1882.2007.tb00002.x 
Rask, K. (2010). Attrition in STEM fields at a liberal arts college: The importance of grades and precollegiate preferences. Economics of Education Review, 29(6), 892-900. doi:10.1016/j.econedurev. 2010.06.013

Richardson, M., Abraham, C., \& Bond, R. (2012). Psychological correlates of university students' academic performance: A systematic review and meta-analysis. Psychological Bulletin, 138(2), 353-387. doi:10.1037/a0026838

Robbins, S. B., Lauver, K., Davis, H. L., Davis, D., \& Langley, R. (2004). Do psychosocial and study skill factors predict college outcomes? A meta-analysis. Psychological Bulletin, 130(2), 261-288. doi:10.1037/0033-2909.130.2.261

Rybczynski, S. M. (2011). Implementation and assessment of non-traditional instructional practices in a college biology course (Doctor of Philosophy). Miami University of Ohio.

Rybczynski, S. M., \& Schussler, E. E. (2013). Effects of instructional model on student attitude in an introductory biology laboratory. International Journal for the Scholarship of Teaching and Learning, 7(2), doi:10.20429/ijsotl.2013.070222

Salta, K., \& Koulougliotis, D. (2015). Assessming motivation to learn chemistry: Adaptation and validation of science motivation questionnaire II with Greek secondary school students. Chemistry Education Research and Practice, 16, 237-250. doi:10.1039/C4RP00196F

Savelsbergh, E. R., Prins, G. T., Rietbergen, C., Fechner, S., Vaessen, B. E., Draijer, J. M., \& Bakker, A. (2016). Effects of innovative science and mathematics teaching on student attitudes and achievement: A meta-analytic study. Educational Research Review, 19, 158-172. doi:10.1016/j. edurev.2016.07.003

Schruba, A. E. (2008). Evaluation of student attitude toward science and self-efficacy in a non-majors college biology course (Master of Education). Texas Christian University. Retrieved from https:// repository.tcu.edu/bitstream/handle/116099117/4103/schruba.pdf?sequence $=1$

Schumm, M. F., \& Bogner, F. X. (2016). Measuring adolescent science motivation. International Journal of Science Education, 38(3), 434-449. doi:10.1080/09500693.2016.1147659

Simon, R. A., Aulls, M. W., Dedic, H., Hubbard, K., \& Hall, N. C. (2015). Exploring student persistence in STEM programs: A motivational model. Canadian Journal of Education, 38(1), 1-27.

Skinner, E. A., \& Belmont, M. J. (1993). Motivation in the classroom: Reciprocal effects of teacher behavior and student engagement across the school year. Journal of Educational Psychology, 85 (4), 571-581. doi:10.1037/0022-0663.85.4.571

Smith, J. L., Lewis, K. L., Hawthorne, L., \& Hodges, S. D. (2013). When trying hard isn't natural: Women's belonging with and motivation for male-dominated STEM fields as a function of effort expenditure concerns. Personality and Social Psychology Bulletin,, 39(2), 131-143. doi: $10.1177 / 0146167212468332$

Spelke, E. S. (2005). Sex differences in intrinsic aptitude for mathematics and science?: A critical review. American Psychologist, 60(9), 950-958. doi:10.1037/0003-066X.60.9.950

Stains, M., Harshman, J., Barker, M. K., Chasteen, S. V., Cole, R., DeChenne-Peters, S. E. ... Young, A. M. (2018). Anatomy of STEM teaching in American Universities. Science, 359(6383), 14681470. doi:10.1126/science.aap8892

Stephens, N. M., Fryberg, S. A., Markus, H. R., Johnson, C. S., \& Covarrubias, R. C. (2012). Unseen disadvantage: How American universities' focus on independence undermines the academic performance of first-generation college students. Journal of Personality and Social Psychology, 102 (6), 1178-1197. doi:10.1037/a0027143

Stevens, T., Olivarez, A., Lan, W. Y., \& Tallent-Runnels, M. K. (2010). Role of mathematics self-efficacy and motivation in mathematics performance across ethnicity. The Journal of Educational Research, 97(4), 208-222. doi:10.3200/JOER.97.4.208-222

Sundberg, M. D., Dini, M. L., \& Li, E. (1994). Decreasing course content improves student comprehension of science and attitudes toward science in freshman biology. Journal of Research in Science Teaching, 31(6), 679-693. doi:10.1002/tea.3660310608

Toven-Lindsey, B., Levis-Fitzgerald, M., Barber, P. H., \& Hasson, T. (2015). Increasing persistence in undergraduate science majors: A model for institutional support of underrepresented students. CBE-Life Sciences Education, 14(2): ar12. doi:10.1187/cbe.14-05-0082 
Valentine, J. C., DuBois, D. L., \& Cooper, H. (2004). The relation between self-beliefs and academic achievement: A meta-analytic review. Educational Psychologist, 39(2), 111-133. doi:10.1207/ s15326985ep3902_3

Wang, M.-T., \& Degol, J. (2013). Motivational pathways to STEM career choices: Using expectancy-value perspective to understand individual and gender differences in STEM fields. Developmental Review, 33, 304-340. doi:10.1016/j.dr.2013.08.001

Young, A., Johnson, G., Hawthorne, M., \& Pugh, J. (2011). Cultural predictors of academic motivation and achievement: A self-deterministic approach. College Student Journal, 45(1), 151-163. Retrieved from https://www.researchgate.net/profile/Adena_Young-Jones/publication/260970420_ Cultural_predictors_of_academic_motivation_and_achievement_A_self-deterministic_approach/ links/0deec532c4ea6d1271000000.pdf

Zusho, A., Pintrich, P. R., \& Coppola, B. (2003). Skill and will: The role of motivation and cognition in the learning of college chemistry. International Journal of Science Education, 25(9), 10811094. doi:10.1080/0950069032000052207 